NBER WORKING PAPER SERIES

\title{
HOW GOOD A DEAL WAS THE TOBACCO SETTLEMENT?: ASSESSING PAYMENTS TO MASSACHUSETTS
}

\author{
David M. Cutler \\ Arnold M. Epstein \\ Richard G. Frank \\ Raymond Hartman \\ Charles King III \\ Joseph P. Newhouse \\ Meredith B. Rosenthal \\ Elizabeth Richardson Vigdor \\ Working Paper 7747 \\ http://www.nber.org/papers/w7747 \\ NATIONAL BUREAU OF ECONOMIC RESEARCH \\ 1050 Massachusetts Avenue \\ Cambridge, MA 02138 \\ June 2000
}

We are grateful to Johanna Myers, Regina Shoykhet, and Jessica Walker for superb research assistance, and to Kip Viscusi for helpful comments. The views expressed herein are those of the authors and not necessarily those of the National Bureau of Economic Research.

(C) 2000 by David M. Cutler, Arnold M. Epstein, Richard G. Frank, Raymond Hartman, Charles King III, Joseph P. Newhouse, Meredith B. Rosenthal, Elizabeth Richardson Vigdor. All rights reserved. Short sections of text, not to exceed two paragraphs, may be quoted without explicit permission provided that full credit, including (C) notice, is given to the source. 
How Good a Deal Was the Tobacco Settlement?: Assessing Payments to Massachusetts David M. Cutler, Arnold M. Epstein, Richard G. Frank, Raymond Hartman, Charles King III, Joseph P. Newhouse, Meredith B. Rosenthal, Elizabeth Richardson Vigdor

NBER Working Paper No. 7747

June 2000

JEL No. I1, K0

\begin{abstract}
$\underline{\text { ABSTRACT }}$
We estimate the increment in Massachusetts Medicaid program costs attributable to smoking from December 20,1991, to 1998. We describe how our methods improve upon earlier estimates of analogous costs at the national level. Current costs to the Massachusetts Medicaid program approximate the payments to Massachusetts under the tobacco settlement of November 1998. Whether these payments are viewed as appropriate compensation for Medicaid costs over time depends upon the rate of increase in future health care costs, the rate of decline in smoking, the proportion of smoking that should be attributed to the actions of the tobacco companies and the likelihood the state would have prevailed at trial. The costs to the Medicaid program are dwarfed by the internal costs to smokers themselves.
\end{abstract}

\author{
David M. Cutler \\ Department of Economics \\ Harvard University \\ Cambridge, MA 02138 \\ dcutler@harvard.edu \\ and NBER
}

Raymond S. Hartman
Cambridge Economics, Inc.
4 Cambridge Center
Cambridge, MA 02142
rhartman@cambridge-econ.com

Meredith B. Rosenthal

School of Public Health

Harvard University

677 Huntington Avenue

Boston, MA 02115

mrosenth@hsph.harvard.edu

\author{
Arnold M. Epstein \\ School of Public Health \\ Harvard University \\ Boston, MA 02115 \\ aepstein@hsph.harvard.edu
}

Charles King III
Harvard Business School
Morgan 187
Soldiers Field Road
Boston, MA 02163
cking@hbs.edu

Elizabeth Richardson Vigdor

Sanford Institute of Public Policy

Duke University

Box 90245

Durham, NC 27708

evigdor@pps.duke.edu

\author{
Richard G. Frank \\ Department of Health Care Policy \\ Harvard Medical School \\ 180 Longwood Avenue \\ Boston, MA 02115 \\ frank@hcp.med.harvard.edu \\ and NBER
Joseph P. Newhouse
Department of Health Care Policy Harvard Medical School
180 Longwood Avenue
Boston, MA 02110
newhouse@hcp.med.harvard.edu and NBER


Litigation pursued by 46 states against the major tobacco companies culminated in the well-publicized settlement of November, 1998. The settlement constitutes the largest payment in any civil litigation in American history. ${ }^{1}$ Although the final amount is contingent upon future events, especially tobacco sales, the tobacco manufacturers have agreed to pay the states through the year 2025 in excess of $\$ 200$ billion (in nominal terms; $\$ 87$ billion if discounted at 7 percent) to compensate for health care expenses incurred by the Medicaid program.

As part of this litigation, we were asked in the Spring of 1998 to estimate health care spending incurred by the Massachusetts Medicaid program that was attributable to smoking. Our estimates were to provide the basis for a claim of damages by the Commonwealth of Massachusetts. In this paper we present our methods for estimating such spending, contrast them with methods used elsewhere in the literature, and examine how the magnitude of the costs is related to the size of the payments under the settlement. While the focus of our empirical analysis is Massachusetts, we generalize when appropriate to the overall settlement.

Work on the Medicaid costs of smoking is aided by a substantial literature on the external costs and benefits of cigarette usage. Original analysis of the external costs of cigarettes examined only Social Security (Shoven et al., 1989) but was later extended to the full range of external effects, including direct medical care costs, payments through health insurance, and non-medical factors such as taxes and life insurance premia (Manning et al., 1989, 1991). Research on the topic has continued, with contributions from the Congressional Budget Office (1998), Gravelle and Zimmerman (1994), and Viscusi (1995, 1999). Most of this literature has focused on the lifetime costs of smoking: given two equivalent people at age 20, where one smokes and the other does not, what is the net external cost to society of the smoker in comparison to the non-smoker? The general consensus of this literature is that the external medical costs of cigarette smoking are high, but that other external benefits from cigarette usage, for example reduced recipiency of Social Security, along with existing excise taxes, may be sufficiently high to make cigarettes on net externally beneficial.

Our approach is related but somewhat different. Rather than compare lifetime spending for smokers and non-smokers, we estimate the amount of Medicaid spending at any point in time

1 Court TV (1998), "States Announce Settlement with Tobacco Companies," November 16, 1998. http://www.courttv.com/trials/tobacco/national/111698_ctv.html. We believe comparisons with prior cases are in nominal dollars, but this settlement probably represents the largest payment in real dollars as well. 
that results from cigarettes. Such a prevalence approach is more appropriate for litigation examining damages in a particular period of time, and is the method followed by most state plaintiffs (Miller, et al, 1998; Miller, et al., 1999). We estimate Medicaid costs for threetypes of services: acute care spending for adults enrolled in the program; long-term care spending for elderly people in nursing homes with smoking-related conditions; and costs for low birthweight infants whose low birthweight is a function of their mother's smoking during pregnancy.

We limit our analysis of the external costs of smoking to the Medicaid program, largely because that was the focus of the state litigation. Others have analyzed the impact on state finances more generally (Viscusi, 1999), and we note these studies below. By focusing on one program, we can produce more detailed, convincing evidence than can analyses that have to contend with multiple programs. Furthermore and perhaps more importantly, our analysis helps resolve a substantial controversy over the tobacco settlement. Many in the public health community view the tobacco companies as having gotten the better of the deal. ${ }^{2}$

Our best estimate is that the current annual cost of smoking to Medicaid in Massachusetts - roughly \$300 million per year -- approximately equals the initial annual payment to Massachusetts under the settlement. By that criterion, the settlement seems generally appropriate. Indeed, one might argue that the settlement is too generous, since it does not adjust the payment for the likelihood the state would have prevailed at trial, nor does it partition out the costs attributable to alleged misbehavior on the part of tobacco companies. To the extent that this misbehavior explains less than 100 percent of total costs, our cost estimates overstate the size of a compensable damage award.

Making calculations about whether the settlement was appropriate in the longer term is more difficult. Future payment amounts depend on future general inflation and the number of packs of cigarettes sold nationally. Because the growth of future payments is capped at the rate of inflation in the Consumer Price Index (CPI) and medical care spending has historically increased at a much higher rate (Newhouse, 1992), future payments are likely to fall short of actual future costs.

2 See, for example, the November 18, 1998 critique of the Tobacco Control Resource Center entitled "The AG Settlement: Short on Time and Money, Long on Loopholes," available at http://www.tobacco.neu.edu/Extra/analysis_of_MSA.htm. Michael Siegel of the Boston University School of Public Health was quoted as estimating that the settlement amount for Massachusetts was too low by a factor of more than four (Boston Globe, December 3, 1998, page B1). 
This shortfall will, however, be mitigated if the number of smokers decreases in the future. To finance the payments, tobacco companies announced a 45 cent per pack price increase immediately after the settlement. This price increase will ceteris paribus reduce the volume of cigarettes sold over time, which in turn will reduce future payments under the settlement as well as future Medicaid costs. Over time, the reduction in Medicaid costs as smoking declines will increasingly offset the reduction in payments from the tobacco companies, assuming the rate of increase in health spending exceeds the increase in the CPI. Thus, the settlement becomes increasingly favorable to the states. Not for many decades, however, does the reduction in Medicaid costs fully offset the reduction in payments from the tobacco companies.

The ultimate answer to the question - Is the settlement amount a good deal for the state? - depends upon future changes in medical costs and smoking rates, as well as the assumed amount of smoking absent the tobacco companies' behavior. If the settlement payments are designed specifically to compensate the states for Medicaid payments attributable to smoking, then the tobacco companies paid approximately the right amount, if future health care costs rise with inflation. Alternatively, if future health care costs grow at a rate higher than general inflation, which is most likely, they paid too little. But if one discounted the losses by the probability of prevailing at trial, or built in a percentage to reflect tobacco industry damages, or thought that smoking would decline rapidly in the future, the payment might be too high.

At the end of the paper, we comment briefly on other impacts of the settlement. Smokers and their families bear the internal costs smoking generates - increased morbidity and shorter life spans. Disregarding the benefits from smoking to the smoker, if these internal costs are considered, the tobacco companies paid far less than the damages, by several orders of magnitude. The happier corollary is that reductions in smoking resulting from the settlement will lead to substantially larger gains than just the dollar payments to states.

The paper proceeds as follows. In Section 1, we broadly describe the health care impacts of smoking and place the impacts on Medicaid in context. In Section 2, we describe our methods for measuring the impact of smoking upon Medicaid, and we present our results for Massachusetts. In Section 3 we compare and contrast our methods with others in the literature. Section 4 addresses the question of whether the settlement was a good deal for the Commonwealth of Massachusetts. 


\section{The Health Impacts of Smoking}

Society bears two costs when a person smokes. The first costs are external costs - costs borne by society at large but not the person who smokes. State Medicaid spending is a typical external cost. Taxpayers at large face additional costs to pay for the medical treatment of those Medicaid beneficiaries who smoked. The litigation pursued by all states was designed to recover damages for these external costs. In addition, there are internal costs - costs borne by the smoker and his or her family. Internal costs may be monetary, for example, monies spent to purchase cigarettes, or non-monetary, such as the costs of increased morbidity and mortality.

\subsection{External Impacts and Costs - the Lifetime Approach and the Annual Budgetary Approach}

Our point of departure is earlier work on the external cost of smoking and other health habits (Manning, et al., 1989, 1991). To understand the external cost framework, consider two otherwise equivalent people, one who smokes and one who does not. At any time $t$, smokers and non-smokers impose external costs to society of $C(S)_{t}$ and $C(N S)_{t}$, respectively, where $S$ indicates smoker and $N S$ indicates non-smoker. The difference between these two values, the net external cost of smoking, may be positive or negative, and in general will differ over the course of a person's lifetime. In their late working and early retirement years, smokers are more likely than non-smokers to suffer from a number of diseases which are expensive to treat, such as lung cancer, coronary heart disease, and emphysema. Thus, smokers will cost society more in private insurance premiums, Medicare costs, and Medicaid costs. At very advanced ages, smokers will disproportionately have died compared to non-smokers and thus there will be savings to society in reduced spending on Social Security, Medicare, and Medicaid. ${ }^{3}$

One might summarize these external costs and benefits of smoking in two ways. The first is the lifetime impact: the present value of these different costs and benefits. Considering two people at roughly the beginning of their smoking life (age 20), the net external cost of smoking is given by the following formula (Manning et al., 1989, 1991):

3 For purposes of litigation, the states took the position that tobacco companies should not profit from products that lead to premature death. We therefore did not quantify this offset in our analysis. 
Lifetime Impact $=\sum_{t=20}^{100}\left[\left[\delta^{t-20} \times \mathrm{P}(\mathrm{A} \mid \mathrm{S})_{t} \times \mathrm{C}(\mathrm{S})_{t}\right]-\left[\delta^{t-20} \times \mathrm{P}(\mathrm{A} \mid \mathrm{NS})_{t} \times \mathrm{C}(\mathrm{NS}) t\right]\right.$

where $\delta=1 /(1+\mathrm{r})$, where $\mathrm{r}$ is the annual discount rate, and $\mathrm{P}(\mathrm{A} \mid \mathrm{S})_{t}$ and $\mathrm{P}(\mathrm{A} \mid \mathrm{NS})_{t}$ are the probability an individual is alive in year $\mathrm{t}$ conditional upon being a smoker or non-smoker respectively.

For purposes of this litigation, the question of interest was the annual budgetary cost of smoking to Medicaid from December 20, 1991 to December 31, 1998. ${ }^{4}$ Effects on other state programs, whether positive or negative, were not considered. To determine the costs to Medicaid over this period, we added up the total amount of external costs resulting from Medicaid-eligible smokers each year and express them in present value.

$$
\text { Budgetary Impact }=\sum_{t=0}^{\infty}\left[\left[\delta^{t} \times(\mathrm{C}(\mathrm{S}) t-\mathrm{C}(\mathrm{NS}) t)\right]\right.
$$

Although this approach is somewhat similar to the lifetime approach in that the external costs of smoking are needed for both, there are a number of important differences between Equations (1) and (2). The first, as already noted, is the definition of external costs. For purposes of the litigation, we define $C$ as costs to the Massachusetts Medicaid program over the relevant time frame rather than all external costs.

A second difference arises if a steady-state assumption that is implicit in equation (1) does not hold. Manning et al. $(1989,1991)$ estimated $\mathrm{P}$ in equation (1) using life tables at a point in time and $\mathrm{C}$ using cross-sectional regression based upon data from the RAND Health Insurance Experiment (Newhouse and the Insurance Experiment Group, 1993) and the National Health Interview Survey (NHIS). Implicitly, this approach estimated external costs in the steady state. One can show that out of steady state the lifetime and annual budgetary approaches can generate different values. Equation (2) does not make any steady-state assumption. Medical spending is counted when it is paid for by Medicaid, not as it accrues. Thus, the number of people smoking at any point in time may bear no relation to the damages from tobacco at that time.

\footnotetext{
4 Judge Sosman ruled that a statute of limitations precluded the state from recovery for periods prior to December
} $20,1991$. 
For purposes of optimal taxation, the lifetime approach is more appropriate. In answering the optimal tax question, one wants to know how much each pack of cigarette consumed adds or subtracts to (the present value of) total lifetime external expenses. For purposes of the tobacco litigation, however, what was required was the total amount of damages during a given time period. For this question, the budgetary impact approach is more appropriate. In effect, we wish to know by how much current and past smoking affects current spending, which is what we estimate below. ${ }^{5}$

\subsection{Internal Impacts and Costs -- The Impacts of Smoking on Mortality and Morbidity}

Smoking is recognized as the leading preventable cause of death in the United States (McGinnis and Foege, 1993), while morbidity (illness) is a much more common outcome of smoking than mortality. Both outcomes have internal costs for smokers and their families, costs that are a key component of the overall economic impact of smoking.

\section{Measuring the Health Impacts of Smoking on the Commonwealth of Massachusetts - Smoking-Attributable Costs to Medicaid}

\subsection{Overview}

We begin our empirical analysis with the annual amounts paid by the Massachusetts Medicaid Program since 1991 to various providers of medical services. We assume Medicaid spending on some types of services is not causally related to smoking (for example, mental retardation) and exclude such spending from consideration. We group the remaining Medicaid expenses into one of three aggregate categories: adult acute care; long-term care; and care for low birthweight babies. Analysis of adult acute care costs is restricted to people aged 18 and older. Analysis of long-term care costs is restricted to people 45 and older. For low birth weight infants, we consider only medical spending in the first year of life; although low birthweight

\footnotetext{
${ }^{5}$ Our methods, however, omit the high rate of spending in their final year of life by those who died, because our sample only includes those who survive; a lifetime approach, of course, would include such spending. Because smokers are at greater risk of death, this makes our estimated values conservative.
} 
babies may well have medical spending after age one as a result of their low birthweight, we do not estimate such spending.

For each of these spending categories, we estimate the proportion of the total Medicaid expenses attributable to smoking. In the case of adult acute care, we develop two estimates of smoking-related expenses. One comes from an inclusive model and the other from a diseasespecific model. The inclusive model decomposes the share of total medical costs attributable to smoking by multiplying total Medicaid costs by the Smoking Attributable Fraction (SAF) - the portion of total medical care utilization which is attributable to smoking by current and former smokers:

Inclusive model smoking-related spending = SAF x Medicaid spending,

The disease-specific model focuses solely upon a narrow subset of diseases that the literature has directly linked to smoking. For diseases $d$ which are related to smoking, the disease-specific smoking-related spending is given by:

Disease-specific model smoking-related spending $=\Sigma_{d} \mathrm{SAF}_{d}$ x Medicaid spending ${ }_{d}$.

Because the disease-specific model considers only certain conditions, we think of it as a conservative lower-bound estimate of smoking-related costs. For example, if smoking increases the length of time a person with gall bladder surgery is in the hospital, but gall bladder surgery is not itself judged to be a result of smoking, the disease-specific model will not count the additional costs of the longer hospital stay as a cost of smoking, while the inclusive model would. We thus expect the inclusive model to provide a more accurate estimate of smokingrelated spending than the disease-specific model.

The smoking attributable fraction depends on two variables: the share of people who smoke, and the relative effect of disease for smokers in comparison to non-smokers. The more common are smokers and the more likely the disease is to affect smokers than non-smokers, the greater is the smoking-attributable fraction.

All of our dollar estimates are expressed in 1998 present values. To calculate the present value of past Medicaid spending we took a weighted-average of federal and state discount rates 
with weights equal to federal and state shares of financing. ${ }^{6}$ In Massachusetts the federal and state shares have been consistently about 50 percent. The resulting (nominal) discount rate used was typically between 5 to 7 percent, corresponding to a real rate of 2 to 5 percent. Because calculations were made only for the seven-year period December 20, 1991 through 1998, present value estimates are not sensitive to small changes in the discount rate. ${ }^{7}$

\subsection{Underlying Data and Their Sources}

Data on Medicaid spending come from the Health Care Financing Administration (HCFA) Forms 64 that states file with the federal government in order to claim federal matching funds. These data summarize total spending by source category, which we aggregated into five summary categories as follows:

Our Spending Categories Inpatient Expenditures:

Outpatient Expenditures:

Long-Term Care:

Other Acute Care:

\section{HCFA 64 Spending Categories}

Inpatient Hospital Services, including Disproportionate Share Adjustments (DSH) to acute care hospitals; Medicare Part A premia paid by Medicaid;

Physician Services; Outpatient Hospital Services; Prescribed Drugs; Other Practitioner Services; Clinic Services; Laboratory and Radiologic Services; Rural Health Clinic Services; Medicare Part B premia paid by Medicaid; Emergency Services for Aliens; and Federally Qualified Health Centers;

Nursing Facility Services; Home Health Services; Home and Community Based Services; Programs of Inclusive Care; Personal Care Services; Targeted Case Management Services; Primary Care Case Management Services; Hospice Benefits; and Other Care Services;

Health Insurance Payments for Qualified Individuals; Medicare Coinsurance and Deductible Payments paid by Medicaid; Other Health Insurance Payments.

6 For the federal discount rate we used the rate over all maturities on Federal Debt and Interest Payments from the Bureau of Public Debt. For the state discount rate, we used the return on a portfolio of investments held by the Commonwealth in the Massachusetts Municipal Depository Trust as identified to us by the Massachusetts Office of Administration and Finance; we assume therefore that state savings in Medicaid would have been invested in this portfolio.

${ }^{7}$ This insensitivity is in contrast to the lifetime method, where benefits and costs 40 or more years in the future are important and the discount rate correspondingly important. 
Non-Attributable

To Smoking:
Intermediate Care Facility Services for the Mentally Retarded; Mental Health Facility Services (Regular and DSH); Dental Services; Family Planning and Screening Services.

We grouped as Non-Attributable those services for which we assume there was no causal link to smoking and disregarded costs for such services. Other Acute Care services, an indeterminate mixture of inpatient and outpatient services, are allocated to inpatient and outpatient spending in proportion to the total of inpatient and outpatient spending in the given year. Adjustments for claims in prior years and collections, which are not available by service type, are allocated in proportion to the dollar totals of each type of service; these adjustments were typically around 5 to 10 percent of the total.

Table 1 summarizes the resulting adjusted Medicaid expenditures for these five aggregate categories for the period 1992 to $1997 .{ }^{8}$ Spending on Medicaid is in total about $\$ 5$ to $\$ 6$ billion per year, roughly one-third of which is for long-term care and the rest is for acute care.

We distribute Medicaid expenditures for each type of service by age and gender using Medicaid claims data. ${ }^{9}$

To estimate the share of current, former, and never smokers ${ }^{10}$ in the Massachusetts Medicaid population, we make use of two Massachusetts surveys which gathered data on Medicaid eligibility and smoking status. The Massachusetts Tobacco Survey (MTS), carried out by the Commonwealth in 1993, surveyed 155 men and 417 women who declared themselves Medicaid-eligible. In 1996 and 1997 the Behavioral Risk Factor Surveillance Survey (BRFSS), carried out nationally by the Centers for Disease Control, included questions on Medicaid eligibility; it surveyed 53 men and 280 women in Massachusetts who were Medicaid eligible. We averaged the smoking rates from these two surveys for each gender with weights proportional to the number of respondents.

\footnotetext{
8 We do not report data for 1991 because we use only 11 days from that year. Our estimates of damages from that year include 11/365 of 1991 spending. We estimated 1998 spending using 1997 spending, assuming that we would adjust our estimate when actual 1998 spending data became available, but after the settlement we did not carry out these adjustments. Thus, our estimates should be low by a modest amount. The reader interested in estimates for the period 1970-1997 should consult Cutler, et. al., [June 15, 1998], Tables III.2-III.4. The total over 1970-1997, net of all adjustments, was $\$ 56.64$ billion.
}

$9 \quad$ We had access to complete claims data for 1982 through June 1997.

10 A never smoker is a person who has smoked fewer than 100 cigarettes in his or her lifetime. 
To assess the validity of the estimated prevalence rates, we compared them with national data from the National Health Interview Survey (NHIS). That survey collected data on smoking habits of Medicaid recipients for the period 1990 to 1994. Given its large sample size, the estimated national rates are quite precise. Table 2 compares the Massachusetts data with the national rate for the 1990-94 period. With the exception of female former-smokers, smoking prevalence rates among the Massachusetts Medicaid population are similar to those of the national Medicaid population and the national low-income population (within 15 percent). Smoking rates among the Medicaid population are significantly higher than those for the population as a whole. We assumed the smoking prevalence rates were constant from 1992 and equal to the level shown in Table $2^{11}$

\subsection{Estimates of Adult Acute Medical Care Spending: The Inclusive Model}

As mentioned above, we develop two estimates of acute care spending attributable to smoking: the inclusive-model and the disease-specific-model. We discuss the inclusive-model estimate here. This estimate starts with inpatient, outpatient, and other acute spending described above and determines the proportion of each attributable to smoking. The SAF for each gender $\left(\mathrm{k}=\right.$ male or female), Medicaid service $\left(\mathrm{c}=\right.$ inpatient or outpatient $\left.{ }^{12}\right)$ and year $(\mathrm{t}=$ year $)$ is defined as:

$$
\mathrm{SAF}_{\mathrm{kct}}=\left[\mathrm{CS}_{\mathrm{kt}} * \text { Excess Use } \mathrm{CS}_{\mathrm{kct}}+\mathrm{FS}_{\mathrm{kt}} * \text { Excess Use } \mathrm{FS}_{\mathrm{kct}}\right] / \text { Baseline Utilization } \mathrm{kct}_{\text {. }}
$$

$\mathrm{CS}_{\mathrm{kt}}\left(\mathrm{FS}_{\mathrm{kt}}\right)$ is the share of current (former) smokers in the Medicaid population, and Excess Use $\mathrm{CS}_{\mathrm{kct}}\left(\right.$ Excess Use $\mathrm{FS}_{\mathrm{kct}}$ ) is the additional utilization of current (former) smokers in comparison to never smokers for each service, gender, and year. The numerator of equation (5) is thus the amount of total service use that would not have occurred if all individuals were never smokers; dividing by baseline utilization converts this to a fraction.

The excess use of medical services by current and by former smokers was estimated using a two-part model similar to that of Manning, et al. $(1989,1991)$. The first equation

11 Other methods for estimating smoking prevalence in each year yielded very similar results.

12 Recall that we allocated "Other Acute Spending" to the Inpatient and Outpatient expenditure categories, as described in Section 2.2 above. 
analyzes whether a person uses any medical services; the second equation explains service use (expressed in logarithmic form) conditional on the person using any. In each case, we relate utilization to smoking status and a host of demographic and other characteristics. We estimate the models for men and women separately. The models are of the form:

$$
\begin{aligned}
& \operatorname{Pr}[\mathrm{Y}>0]=\mathrm{a}_{1} * \mathrm{CS}+\mathrm{a}_{2} * \mathrm{FS}+\mathrm{XA}+\mathrm{u} \\
& \log [\mathrm{Y} \mid(\mathrm{Y}>0)]=\mathrm{b}_{1} * \mathrm{CS}+\mathrm{b}_{2} * \mathrm{FS}+\mathrm{XB}+\mathrm{e}
\end{aligned}
$$

The dependent variable $\mathrm{Y}$ is expressed as either inpatient days or physician visits. We use inpatient days to determine the share of inpatient expenditures attributable to smoking and physician visits to determine the share of outpatient expenditures. Since our data indicate whether hospitalization was related to pregnancy or not, and since pregnancy is not causally related to smoking, our measure of hospital days excludes days associated with childbirth.

Assuming the error term $\mathrm{u}$ is normally distributed, equation (6) can be estimated using a probit model. We estimate equation (7) using Ordinary Least Squares.

The source of our data is the 1990-94 National Health Interview Surveys. The NHIS surveys about 100,000 people per year, making our samples particularly large. The NHIS also contains a particularly rich collection of socioeconomic and behavioral controls. Our explanatory variables include age (in 5 year intervals from age 20 through age 100); income ( $\$ 10,000$ increments to $\$ 49,999, \$ 50,000+$ ); education (less than high school, high school graduate, some college, college graduate); race (white, nonwhite); marital status (married, widowed/divorced/separated, single); class of worker (private sector, government, selfemployed, not working, other); region (four census regions); metropolitan area (MSA central city, MSA non-central city, non-MSA farm, non-MSA non-farm); health insurance (Medicare, Medicaid, CHAMPUS, private, none); body mass index and its square; year dummy variables; and dummy variables for industry and occupation. In addition, the 1991 survey asked about drinking status (no drinks, 1-2 drinks/day in the past two weeks; $3+$ drinks/day in the past two weeks); trying to lose weight (yes, no); exercise (dummy variable for exercise within the last two weeks); add salt to food (yes, no); pipe smoker (yes, no); cigar smoker (yes, no); and user of smokeless tobacco (yes, no). 
The coefficients on the smoking variables from equations estimated over the 1990-94 period (and thus without the variables in 1991 only) are presented in Table $3 .{ }^{13}$ Not surprisingly, given the size of the sample, all these coefficients are precisely estimated. We use these coefficients to predict utilization for each Medicaid-eligible individual in the NHIS sample within each smoking group (current and former). To retransform the predicted value for the logarithm of dollars to raw dollars, we first computed Duan's smearing factor for each smoking group (i.e., the average of the exponentiated residuals within that group (Duan, 1983)). We then multiply the predicted probability of positive expenditure, the exponentiated predicted logarithm of services used, and the appropriate smearing factor to form a prediction of expected utilization for each person. Finally, we average these predictions across all Medicaid-eligibles within each smoking group, which we denote as "Average Predicted Use CS" and "Average Predicted Use FS" for current and former smokers.

We then predict utilization for each current and former smoker assuming that that individual had never smoked, by setting the CS and FS variables to 0 . We denote the resulting average predicted utilization if the current or former smoker had never smoked as "Average Predicted Use CS if NS" and "Average Predicted Use FS if NS." The excess utilization of current and former smokers is the difference between their predicted utilization given their smoking status and their predicted utilization if they had never smoked, that is,

Excess Use CS $=$ Average Predicted Use CS - Average Predicted Use CS if NS

Excess Use FS = Average Predicted Use FS - Average Predicted Use FS if NS

The last rows of Table 3 show the percentage by which utilization of smokers exceeds that of never smokers. Both male and female current and former smokers have many more hospital days than do nonsmokers. For example, current male smokers have 31 percent more hospital days; former male smokers have about 42 percent more hospital days; and current and former female smokers have 24 percent and 26 percent more hospital days, respectively. Likewise both male and female current and former smokers have more physician visits. The

\footnotetext{
${ }^{13}$ Full coefficient estimates are available in Cutler et al. [July 1, 1998].
} 
effect on physician visits is much smaller than for hospital days; there were 12 to 16 percent more visits among former smokers and 3 to 4 percent more among current smokers.

We make several adjustments to these estimates. First, we back out hospital utilization attributable to mental illness, under the assumption that mental illness is not related to smoking. The 1990-94 NHIS does not include information on diagnosis for hospital stays, but the 19781980 NHIS does. We computed the ratio of hospital days without mental health diagnoses to hospital days including mental health diagnoses for the 1978-1980 period for current, former, and never smokers and, within these groups, for men and women. We then multiplied predicted hospital days in the 1990-1994 surveys, which include mental health diagnoses, by these ratios. In light of the decrease of inpatient use of mental health care in the Massachusetts Medicaid program since the introduction of managed behavioral health care in the $1990 \mathrm{~s},{ }^{14}$ this adjustment is conservative.

Second, we made adjustments for additional behavioral factors that affect medical care utilization but that are not collected in all years of the survey. A subset of the independent variables (noted above) were available only in the 1991 NHIS. We estimated auxiliary regressions using the 1991 data, with and without controls for these additional variables. The difference between these two estimates was used to adjust the results for the entire 1990-94 sample. $^{15}$

Table 4 demonstrates how adding these additional controls affect the estimates of smoking-related utilization. ${ }^{16}$ The effect of adding the additional covariates is modest. For example, without the additional variables, current-smoking males have 6 percent higher physician visits; with them, they have 3 percent higher visits. In many cases, adding in these variables increases the size of the smoking effect; for example, the effect on physician visits for current-smoking women increases from 8 percent to 10 percent more visits. We do not have an

14 Frank, et al. (1996) show reductions of inpatient days per 1000 Medicaid enrollees of over 40 percent between 1991 and 1995.

15 Specifically, we predicted utilization of medical services from the 1991 data with and without these variables, separately for men and women and for hospital and physician services. We then formed the ratio of utilization predicted when these factors were included to utilization predicted when these factors were excluded. The estimates for the entire 1990-94 period were scaled by this ratio.

16 The estimates without the additional variables differ from those in Table 3 because they are based on only the 1991 data. 
obvious explanation for why additional controls increases the smoking effect, although many risk factors are different for the low-income population in comparison to the high income population. Our rich socioeconomic controls may also mitigate the impact of these additional behavioral factors.

These measures of excess use, adjusted for mental health visits and the additional control variables in 1991, enter the numerator of the Smoking-Attributable Fraction in equation (5). The denominator of equation (5), Baseline Utilization of health care services, is total physician visits or hospital days in the relevant NHIS sample.

Combining these estimates, we obtain the SAFs presented in Table 5. We estimate that smoking accounts for 3 to 7 percent of physician visits, and 15 to 23 percent of hospital days.

Applying the resulting SAFs to the Medicaid expenditures grouped as shown in Table 1, we calculate total smoking-attributable Medicaid spending on adult acute care between December 20, 1991 and 1998 using the inclusive approach to be \$1.5 billion in 1998 dollars. On an annual basis, smoking-attributable Medicaid spending for adult acute care is roughly $\$ 215$ million.

\subsection{Estimates of Adult Acute Medical Care Spending: The Disease-Specific Approach}

Our disease-specific methodology is designed to estimate spending for diseases where the link with smoking is particularly well established. Following equation (4), the goal is to estimate the smoking attributable share of particular diseases and multiply this by total spending on those diseases. Estimating total spending for a disease is difficult, since claims data are not perfect. For example, a person with lung cancer will have claims for 'routine physician visits' and possibly 'radiologic or laboratory services'. It is not always obvious whether services provided were for the treatment of lung cancer or not.

We designed a methodology to account for this. We start by adding up all the claims for people who were diagnosed with each smoking-related condition. We then subtract from average spending for these people the average spending for people with no smoking-related conditions. The resulting Disease-Specific Spending Differential (DSSD) is an estimate of per person smoking-related spending for that condition. 
Denoting diseases as $d$ and demographic groups as $k$, the disease-specific estimate of Medicaid spending attributable to smoking is the product of the smoking attributable fraction, the disease-specific spending differential, and the number of Medicaid beneficiaries with that disease:

$$
\begin{aligned}
& \text { Disease-Specific Medicaid Spending Attributable to Smoking } \\
& =\Sigma_{d}\left\{\Sigma_{k} \mathrm{SAF}_{d k} * \text { Disease-Specific Spending Differential } d k *\right. \\
& \left.\quad \text { Number of Medicaid Beneficiaries with Smoking-Related Disease } d_{k k} .\right\}
\end{aligned}
$$

To implement this analysis one must first determine the list of conditions related to smoking. Perhaps the best-known recent review of smoking-related diseases is the 1989 Surgeon General's Report (U.S. Department of Health and Human Services, 1989). We started with the Surgeon General's report and supplemented it with a MEDLINE search of the more recent medical literature to develop a list of conditions for which we concluded there was very strong evidence of causation.

For a disease to be included, the literature must indicate how smoking influences the probability of disease. This is typically expressed as a relative risk - the odds of disease for smokers in comparison to never smokers. The smoking attributable fraction for each disease is a straightforward combination of the relative risk and the share of smokers in the population. ${ }^{17}$ The most widely used approach to assess relative risks is to measure disease rates in a large sample population containing both smokers and nonsmokers. ${ }^{18}$ For many diseases, death rates

${ }^{17}$ Denoting NS, CS, and FS as never, current, and former smoking rates, and RR as the relative risk (the odds of disease for smokers in comparison to non-smokers), the equation for the SAF is:

$$
S A F_{d k}=\frac{\left[N S_{k}+C S_{k}\left(R R_{d k C S}\right)+F S_{k}\left(R R_{d k F S}\right)-1\right]}{N S_{k}+C S_{k}\left(R R_{d k C S}\right)+F S_{k}\left(R R_{d k F S}\right)}
$$

18 Disease-specific relative risks for smoking-related diseases have been calculated from several large prospective studies of smoking and mortality (Hammond, 1966; Kahn, 1966; Doll and Peto, 1976; Cederlof et al., 1977; Doll et al., 1980; Stellman and Garfinkel, 1986; US Department of Health and Human Services, 1989; Doll et al., 1994). The most common of these is the American Cancer Society's Cancer Prevention Study II (CPS-II), a four-year (1982-86) follow-up study of 1.2 million persons (USDHHS, 1989). Relative risk for smoking differs 
are both more accessible and reliable than disease rates. Accordingly, some of our calculations use the relative risk of mortality from smoking as a proxy for the relative risk of disease. Importantly, we only had relative risks for a subset of the diseases we identified as related to smoking. Thus, our list of conditions yields a quite conservative estimate.

The first column of Table 6 presents the diseases we include. Three classes of diseases are related to smoking: neoplasms (cancer); cardiovascular disease; and respiratory disease. Relative risks for cancer are quite high (as high as 30:1). Relative risks for cardiovascular disease and respiratory disease range from $2: 1$ to $10: 1 .^{19}$

Using our estimated rates of current and former smokers in each year, we then calculated disease-specific SAFs for all years. The SAFs differ by age and gender (because relative risks differ by age and gender) and year (because smoking prevalence varies by year). In Table 6, we report age- and gender-specific SAFs for 1998 by disease. Typical smoking-attributable shares are between one-third and two-thirds, with some numbers as high as 90 percent (certain cancers).

The next step is to calculate the Disease-Specific Spending Differential for each condition. To calculate the DSSD, we start by identifying all Medicaid recipients with each smoking-related condition. For recipients with two or more smoking-related diseases, we assign the person to the first reported diagnosis in time and attribute their dollars to that diagnosis. We average the Medicaid claims for all recipients with each smoking-related disease by age and gender groups over the period 1991 through 1998. We also average the claims of all Medicaid recipients who had none of the diseases identified in Table 6, again by age and gender. ${ }^{20}$ The base for the DSSD is the difference between these two averages.

This difference was adjusted for four factors. First, spending related to pregnancy, mental disorders, substance abuse and AIDS was eliminated for both groups of enrollees (those with and without smoking-related diseases) on the grounds that spending on these conditions was not related to smoking. Second, because 1997 claims data were incomplete at the time we carried out the analysis and because 1998 data were not yet available, we assume that nominal spending

by gender and study population (US Department of Health, Education, and Welfare, 1979; US Department of Health and Human Services, 1989).

${ }^{19}$ For more details on the disease-specific estimates, including a complete set of relative risks, SAFs, and estimated smoking costs, see Cutler, et. al., July 11, 1998.

${ }^{20}$ We include in this latter group people with no claims during the year. 
in those two years remained constant at the 1996 levels. This assumption produces conservative calculations of damages. Third, because payments for HMO enrollees are not captured in the Medicaid claims, we grossed up spending for HMO enrollment. ${ }^{21}$ Fourth, we added in disproportionate share (DSH) payments to acute care hospitals and subtracted drug rebate funds. $^{22}$ DSH funds are additions to Medicaid to account for costs not included in direct claims. We in effect assume these costs have a similar distribution to Medicaid costs.

Finally, to calculate total smoking-attributable spending we multiply the DSSD by the number of Medicaid recipients in each disease, age and gender category and by the SAF for that category and sum the results across age and gender categories. The last column of Table 6 reports the smoking-attributable spending for each disease for the December 20, 1991 through December 31, 1998 time period. We calculate total smoking-attributable Medicaid spending on acute care services for adults using the disease-specific approach to be just under \$1 billion (\$923 million) in 1998 dollars, or roughly \$132 million on an annual basis. The largest contributors to this are respiratory diseases and cerebrovascular disease. Lung cancers are also important.

The disease-specific estimate is two-thirds of the estimate derived using the inclusive model ( $\$ 1.5$ billion). The disease-specific estimate should be lower than the inclusive model estimate, since it is a more conservative approach. Indeed, the magnitude of the difference seems reasonable.

${ }^{21}$ The adjustment factor is given by:

$$
\text { HMO Adjustment }=1+\frac{(\text { HMO Adult Enrollees })}{(\text { Non HMO Adult Enrollees })}
$$

In effect, this assumes that the percentage increment in HMO spending for adult enrollees is similar to the percentage increment in non-HMO acute care spending. Ideally this adjustment would have been age and gender specific, but we were unable to obtain age-gender specific HMO enrollment when we were carrying out the calculations.

${ }^{22}$ This adjustment factor is

$$
\text { DSH Adjustment }=\left[1+\frac{(\text { DSH Hospital Payments }- \text { Drug Rebates })}{(\text { Total Acute Care Spending Identified in Claims Data })}\right]
$$

DSH payments to mental hospitals were excluded. 


\subsection{Long-Term Care Spending}

Spending for long-term care (LTC) represents 30 to 40 percent of total Medicaid spending depending on the year. Our approach to long-term care spending is similar to the disease-specific approach for adult acute care. In particular, attributable spending in year $t$ is defined as:

Smoking-attributable long-term care costs

$$
=\left\{\sum_{d} S A F_{d} * \text { Share of residents with disease }\right\}^{*} \text { Total nursing home costs } t_{t}
$$

The SAF is the same as for the disease-specific model, although we use smoking prevalence data from the population aged 45 and older rather than the entire adult population, since we assume long-term care use for people under 45 is not related to smoking. Data on admission diagnoses for nursing home residents are from the 1995 National Nursing Home Survey. We compute diagnosis of admission for all residents age 45 and older. Table 7 presents for men and women the share of nursing home stays by disease, the smoking attributable share of each disease and the share of nursing home stays resulting from smoking. Smoking-related diagnoses in total account for 5.1\% of 1998 nursing home admissions of women. For men, this total is $11.0 \%$ of nursing home admissions. The largest contributors are cerebrovascular diseases, chronic airways obstructions, other heart disease, and bronchitis/emphysema.

Multiplying the smoking-related share of nursing home expenses by total nursing home spending in Table 1 yields an estimate of smoking-related costs for each disease, shown in the last column of Table 7. We estimate long-term care spending attributable to smoking at about \$700 million in total over the December 20, 1991 through 1998 period -- \$291million for men and $\$ 410$ million for women. This is roughly $\$ 100$ million on an annual basis (men and women combined). The largest contributors to this total are chronic airways obstructions, cerebrovascular disease, other heart disease, and bronchitis/emphysema. 


\title{
2.6. Low Birthweight Babies
}

Costs for low birthweight (LBW) babies are estimated using an approach similar to the disease-specific approach. In particular, the costs for year $t$ are computed as the product of the smoking-attributable share of low birthweight births, the additional spending on low birthweight births, and the total number of low birthweight babies:

\author{
Smoking-attributable LBW Costs \\ $=\mathrm{SAF} *$ Differential Spending for Low Birthweight $\operatorname{Birth}_{t} *$ \\ Number of Low Birthweight Births $s_{t}$
}

The effect of smoking during pregnancy on the incidence of low birthweight is addressed in the medical literature. Epidemiological evidence suggests that only current smoking by the mother influences the risk of low birthweight. We thus limit the SAF to this one risk factor. Three different studies (Meyer, Jonas, Tonascia, 1976; McIntosh, 1984; Kramer, 1987) are cited in the Surgeon General's Report (1989) as measuring the relative risk of low birthweight for smokers. The estimates range from 1.81 to 2.21 . We used a relative risk of 1.81 to be conservative. The smoking-attributable fraction of low birthweight births implied by these estimates is about 22 percent. $^{23}$

The data on differential spending for LBW births came from the claims data. We selected all claims with an International Classification of Disease (ICD) code of 764 or 765 (indicating low birthweight) for the low birthweight sample and births with code of v30 and not 764-765 (indicating normal birthweight) for the normal birthweight sample. ${ }^{24} \mathrm{We}$ then computed the difference in average spending for each group in the first year of life. As above, we

\footnotetext{
${ }^{23}$ Our Massachusetts smoking surveys are not large enough to estimate smoking rates among pregnant women covered by Medicaid in Massachusetts. We thus impute smoking rates for pregnant women using other data. The National Maternal and Infant Health Survey of 1988 estimates that 34.5 percent of women in Massachusetts whose birth was covered by Medicaid reported smoking during their pregnancy. We trended this over time using NHIS data on the share of new mothers who smoked. This percentage did not change greatly over the time period, so the percentage of Medicaid-covered births to women who smoke was essentially constant.

In subsequent work we concluded that it was appropriate to exclude a minority of those cases with ICD-9 codes beginning with 764 and 765. Specifically, those claims where the fifth digit of the ICD-9 code was equal to 9 were believed to be premature but not technically low birthweight. Exploratory analyses indicate that excluding these births would have only minimal effects on our estimates.
}

24 
adjusted these numbers for HMO enrollment, DSH payments, and drug rebates. Multiplying by the number of low birthweight births gives an estimated total cost of low birthweight births attributable to smoking of \$21 million over the December 20, 1991 through 1998 period, or \$3 million on an annual basis.

\subsection{Summary of Medicaid Expenditures Attributable to Smoking}

To summarize, the total Medicaid expenditures attributable to smoking over the damage period defined by the court are the following:

\section{Smoking-Attributable Expenditures (millions 1998 \$)}

\begin{tabular}{|c|c|c|}
\hline & 1991-98 & $\begin{array}{l}\text { Annual } \\
\text { Average }\end{array}$ \\
\hline \multicolumn{3}{|l|}{ Adult Acute Care } \\
\hline Inclusive Model & $\$ 1,498$ & $\$ 215$ \\
\hline Disease-Specific Model & 923 & 132 \\
\hline Long Term Care & 701 & 100 \\
\hline Low Birth Weight Births & 21 & 3 \\
\hline \multicolumn{3}{|l|}{ Totals } \\
\hline Using the Inclusive Model & $\$ 2,220$ & $\$ 318$ \\
\hline Using the Disease-Specific Model & 1,645 & 235 \\
\hline
\end{tabular}

On an average annual basis, total Medicaid costs attributable to smoking are \$318 million using the inclusive model and \$235 million using the disease-specific model ( $\$ 2.22$ billion and $\$ 1.65$ billion over the entire 1991-98 period). This amounts to about 7 percent of Medicaid spending for inpatient, outpatient and long-term care over this period and approximately 5.6\% of total Medicaid expenditures. We believe the total using the inclusive model to be the more appropriate and more accurate estimate.

On a per pack basis, these estimates imply implies annual external costs of roughly $\$ .75$ This number is higher than the national average (about $\$ .30$ per pack), largely because tax rates in Massachusetts are much higher than the nation as a whole, and thus current smoking rates in 
Massachusetts are below the national rate. ${ }^{25}$ Per Medicaid smoker, the estimate of damages is even higher - about $\$ 6$ per pack. This compares with estimates of external costs of smoking on a lifetime basis of roughly $\$ .40$ per pack in the late 1980s (Manning et al., 1991).

While the external cost per Medicaid smoker seems particularly high, there are several reasons for this value. First, the costs of former smokers are included in the Medicaid spending, but the cigarettes they consumed are not. A related point is that the number of smokers has been declining in recent years, as a result of price increases and secular declines in smoking rates. But Medicaid spending today is at least partly a result of the higher smoking rates in the past. Thus, damages per current user are much higher than damages per pack of cigarettes consumed over the relevant time period. Second, because many people do not enroll in Medicaid until they become sick, the number of current smokers on Medicaid is below the number of current smokers in the population whose medical expenses will ultimately be paid for by Medicaid. For these reasons, $\$ 6$ per pack is not an estimate of the external costs of each pack of cigarettes smoked.

Despite these differences in costs per pack using the annual and the lifetime approaches, the estimated percentage of Medicaid spending that we attributed to smoking using the 19781980 data was close to the value from the 1990-1994 data. For physician visits, the smoking attributable share of spending in 1978-80 is 1.3 percent for men and 7.5 percent for women (versus 2.5 percent and 6.7 percent in 1990-94); for hospital visits, the shares are 23.5 percent for men and 17.8 percent for women in 1978-80 (versus 23.2 percent and 14.7 percent in 1990-94). This similarity is reassuring, in that it suggests our values are robust despite changes in behavior over time.

\section{Comparison with Other Efforts}

In designing our analysis, we had the luxury of examining the efforts undertaken by experts in other states as well as a substantial economic literature on the costs of smoking.

\footnotetext{
${ }^{25}$ Cigarette prices averaged \$1.97 in 1998 for the nation as a whole, and \$2.79 in Massachusetts. Massachusetts consumed 1.7 percent of the nation's cigarettes, while it has 2.3 percent of the population. Taking a demand elasticity of -0.4 , one would predict that the higher prices in Massachusetts would have lowered consumption by 17 percent, or equivalently that Massachusetts would account for 1.9 percent of the nation's cigarette consumption. Thus, two-thirds of lower cigarette consumption in the state can be explained by higher prices. See Cutler et al. (2000) for details.
} 
The economic literature on this topic differs fundamentally from ours. Most of the literature focuses on the total external costs of smoking, while we focus on the Medicaid component only. Our focus on Medicaid allows us to develop better estimates of smokingattributable costs for that program - for example the disease-specific approach. But in exchange, we cannot say anything about the total social sector impact of the tobacco settlement.

Some literature suggests that the tobacco settlement as a whole was too generous when the public sector is considered in toto. Viscusi (1999), for example, concludes that cigarettes are always self-financing in terms of costs to state governments. But Viscusi's methodology is very different from ours. Most importantly, Viscusi considers as costs only the state's share of Medicaid spending. We include the Federal share as well, on the grounds that the division of this amount between Federal and state coffers is not particularly relevant to the overall merits of the settlement.

A more closely related literature is the damage estimates in other states. The case in Minnesota was developed most fully, although other states had done analysis as well (Miller et al., 1998, 1999). These cases have drawn substantial controversy, with some authors arguing that estimates of damages put forward by the states were too large (Rubin, 1998).

There are several points of contention. First, some authors criticize the methods for determining the smoking-attributable share of medical costs. The major challenge in the SAF calculations is to separate out the effect of smoking from other factors. One concern, discussed above, is that not all factors that influence medical spending are recorded on surveys. A second concern is that the non-smokers are not sufficiently comparable to the smokers on dimensions that can be observed. To take a concrete example, consider the age distribution of smokers and non-smokers. Because never smokers tend on average to be younger than current or former smokers (reflecting the decline in smoking among youth since 1964), misspecification of the functional form relating medical care utilization to age can appear as bias in the estimates of the smoking effect. For example, if the true effect of age were quadratic and age were entered as a linear function, some of the age effect would appear as a smoking effect. Rubin (1998) showed that the Miller et al. estimates changed when propensity scores were used to match observations.

To address this in our models, we imposed minimal functional form assumptions in our utilization equations. Virtually all variables were broken up into rather small discrete intervals. Age, for example, was coded as a dummy variable for each five-year interval and was gender- 
specific (i.e., was fully interacted with gender), in contrast to the Miller et al. analysis for Minnesota, which grouped age into three age groups and was not gender-specific. In the case of our analysis, the use of propensity scores caused minimal change in the results (Rosenthal et al., forthcoming).

A second issue is the source of data. Most analyses of smoking-attributable medical costs use data from the National Medical Expenditure Survey (NMES) of 1987. This can be criticized on several grounds. The sample size in the NMES is relatively small, with only about 35,000 people. The NHIS samples we employ, in contrast, have over 100,000 people in each year. The additional sample size not only allows for more precise estimates, but also permits us to impose fewer functional form assumptions without danger of overfitting (Duan et al., 1983). In addition, many of the smoking responses in the NMES were imputed, where this was not the case in the NHIS. Imputation of the key independent variable is clearly an important drawback. Finally, the NMES was only conducted once, in 1987. Because the NHIS asks smoking questions in many years, we could compare results from an earlier period (1978-80) with the more recent period (1990-94). Our finding that smoking had relatively similar effects on medical care utilization in the two time periods lends substantially more credence to the results.

Despite these differences, the estimates in the NHIS and the NMES are relatively close. Miller et al. estimate that total acute care spending in the population is 6.2 percent higher because of smoking and that it is 4.6 percent higher in the national Medicaid population (Miller et al., 1997, Table 2.9). Our comparable estimate for the Massachusetts Medicaid population is 5.6 percent over 1991-1998 (see Section 2.7 above).

\section{Policy Analysis: Was the Settlement Big Enough?}

We estimate the costs of smoking to Medicaid in Massachusetts at about \$318 million annually, roughly 5-6 percent of Medicaid spending. This is quite close to the amount that the tobacco companies will pay Massachusetts. Massachusetts' payments are expected to range between \$234 million in 2000 and \$374 million in 2010, with an average payment of \$307 million in that span. Clearly, costs in other states could differ, depending on smoking prevalence among the Medicaid population, patterns of treatment for smoking-related disease, and the generosity of the state's Medicaid program in terms of eligibility, covered services, and provider 
reimbursement. Nonetheless, our estimates for Massachusetts suggest the settlement amounts were reasonably in line with costs based upon smoking-attributable Medicaid expenditures.

If the goal is to compensate states for the Medicaid costs of smoking, the settlement appears right in the initial years. Indeed, one might even argue that the settlement is too generous. After all, it is not obvious that the Commonwealth would have prevailed at trial. The expected value of the legal case is thus below our damage estimates. Further, not all of the Medicaid costs are a result of the alleged misbehavior on the part of tobacco companies. If the goal of the litigation was to compensate states for Medicaid costs resulting from misbehavior on the part of tobacco companies, one would need to reduce our cost estimates by the share of smoking resulting from the tobacco companies' misbehavior.

After the initial years, the financial payments of the settlement will be adjusted upward by 3 percent per year or the increase in the Consumer Price Index,${ }^{26}$ whichever is greater. However, even though the payment streams will grow with inflation, it is unlikely that they will keep pace with the growth in medical costs generally and the growth in smoking-attributable Medicaid costs specifically. Hence, over time, this factor makes the settlement less favorable to the state.

Over time, the payments will be adjusted downward with reductions in national cigarette smoking. Cigarette smoking in the country as a whole has declined on average 1.2 percent per year in the past few decades. Allowing for some slowdown in that decline in future decades, we estimate that absent the settlement smoking will decline 16 percent by $2025 .^{27}$ The price and counteradvertising effects implemented by the settlement will, we estimate, further reduce smoking by another 11 percent.

The effect of this volume reduction will be to lower payments to Massachusetts. It also lowers Medicaid spending for smoking-related diseases. In the situation where Medicaid spending increases more rapidly than inflation, so that the settlement falls short of full compensation for smoking-related illnesses over time, additional smoking reductions are good for the state - they lower costs to Medicaid by more than the reduction in payments. But this effect is not large; the fiscal picture is not balanced for many decades. Thus, if medical costs

\footnotetext{
26 For comparison, the rate of inflation over the last 50 years has been 4 percent.

27 Our projections are laid out in detail in Cutler et al. (2000).
} 
continue to increase at near their historical rate, the settlement will be unfavorable to the state for many decades into the future.

While the reductions in Medicaid health care costs are important, the economic benefits from the reduction in smoking-related mortality and morbidity may be orders of magnitude larger. In other work (Cutler et al., 2000), we estimate that the value of the incremental increase in longevity resulting from the settlement will amount to about $\$ 60$ billion in present value through 2025. These savings dwarf the size of the financial payments and reductions in Medicaid spending. Moreover, these savings do not include valuations of the substantial reductions in morbidity induced by the settlement.

These estimates, however, do not impute any benefit to the smoker from smoking. Rational addiction models imply that these mortality-related costs should be more than offset by assumed benefits to smokers (Becker and Murphy, 1988; Becker, Grossman, and Murphy, 1991, 1994). Whether this argument should prevail is an issue we discuss elsewhere (Cutler et al., 2000). Although we conclude that it should not, if it were to prevail these averted internal costs should not be counted as a benefit of the settlement. 


\section{REFERENCES}

Basu, Joy, "Data View: Border Crossing Adjustment and Personal Health Care Spending by State," Health Care Financing Review, , 18(1): 215-236, Fall 1996.

Becker, Gary S., and Kevin M. Murphy, "A Theory of Rational Addiction,” Journal of Political Economy, 96:675-700, 1988.

Becker, Gary S., Michael Grossman, and Kevin M. Murphy, "Rational Addiction and the Effect of Price on Consumption," American Economic Review, 81:237-241, 1991.

Becker, Gary S., Michael Grossman, and Kevin M. Murphy, “An Empirical Analysis of Cigarette Addiction,” American Economic Review, 84:396-418, 1994.

Cederlof R, Friberg Lars, Lundman T., "The Interactions of Smoking, Environment and Heredity and Their Implications for Disease Etiology. A Report of Epidemiological Studies on the Swedish Twin Registries,” Acta Medica Scandinavica Supplementum, 612:1-128, 1977.

Congressional Budget Office, "The Proposed Tobacco Settlement: Issues from a Federal Perspective," Washington: CBO, April 1998.

Court TV, "States Announce Settlement with Tobacco Companies," http://www.courttv.com/trials/tobacco/national/111698_ctv.html. November 16, 1998.

Cutler, David M., Mark McClellan, and Joseph P. Newhouse, "The Costs and Benefits of Intensive Treatment for Cardiovascular Disease," in Measuring the Prices of Medical Treatments, ed., Jack Triplett; Washington: The Brookings Institution, 1999.

Cutler, David M., Arnold M. Epstein, Richard G. Frank, Raymond S. Hartman, Charles King and Joseph P. Newhouse, "The Impact of Smoking on Medicaid Spending in Massachusetts: 19701997: Methods, June, 15, 1998.

, "The Impact of Smoking on Medicaid Spending in Massachusetts: 19701998: Results From the Inclusive Approach for Adults," July 1, 1998.

, "The Impact of Smoking on Medicaid Spending in Massachusetts: 19911998: Results From the Disease-Specific Approach for Adults and Overall Summary," July 11, 1998.

Cutler, David M., Jonathan Gruber, Raymond S. Hartman, Mary Beth Landrum, Joseph P. Newhouse and Meredith B. Rosenthal, "Some Measures of the Economic Impacts of the Tobacco Settlement," forthcoming.

Doll R and Peto R, "Mortality in Relation to Smoking: 20 Years' Observations on Male British Doctors," British Medical Journal, 2:1525-1536, 1976. 
Doll R, Gray R, Hafner B, Peto R, “Mortality in Relation to Smoking: 22 Years' Observations on Female British Doctors," British Medical Journal, 280:967-971, 1980.

Doll R, Peto R, Wheatley K, Gray R, and Wheatley K, "Mortality in Relation to Smoking: 40 Years' of Observations on Male British Doctors," British Medical Journal, 309:901-911, 1994.

Duan, Naihua, "Smearing Estimate: A Nonparametric Retransformation Method," Journal of the American Statistical Association, 78:605-610, 1983.

Duan, Naihua, Willard G. Manning, Carl N. Morris, and Joseph P. Newhouse, "A Comparison of Alternative Models for the Demand for Medical Care," Journal of Business and Economic Statistics, 1(2):115-126, April 1983.

Frank, Richard. G., Thomas G. McGuire, Elizabeth H. Notman, and Rebecca M. Woodward, "Developments in Managed Behavioral Health Care" in R. Manderscheid and M. Sonnenschein (Eds) Mental Health U.S., 1996. Washington: USGPO, 1996.

Gravelle, Jane, and Dennis Zimmerman, Cigarette Taxes to Fund Health Care Reform: An Economic Analysis, Washington, D.C.: Congressional Research Service, 1994.

Hammond E. Culyer, "Smoking in Relation to the Death Rates of One Million Men and Women," National Cancer Institute Monograph, 19:127-204, 1966.

Kahn H.A., "The Dorn Study of Smoking and Mortality among U.S. Veterans: Report on Eight and One-Half Years of Observation," National Cancer Institute Monograph, 19:1-125, (1966).

Kramer M. S., “Intrauterine Growth and Gestational Duration Determinants," Pediatrics, 80:502-511, 1987.

Lamphere, JoAnn, Normandy Brangan, Sharon Bee, and Rafael Semansky, "Reforming the Health Care System: State Profiles 1998," Washington: American Association of Retired Persons, 1998.

McGinnis J.Michael and William H. Foege, "Actual Causes of Death in the United States," Journal of the American Medical Association, 270:2207-2212, 1993.

McIntosh. I.D., "Smoking and Pregnancy: Attributable Risks and Public Health Implications," Canadian Journal of Public Health/Revue Canadienne de Sante Publique, 75(2):141-8, 1984.

Meyer M.B., B.S. Jonas, and J.A. Tonascia, "Perinatal Events Associated with Maternal Smoking During Pregnancy," American Journal of Epidemiology, 103:464-476, 1976.

Manning, Willard G., Emmett B. Keeler, Joseph P. Newhouse, Elizabeth M. Sloss, and Jeffrey Wasserman, "The Taxes of Sin: Do Smokers and Drinkers Pay Their Way?" Journal of the American Medical Association, 261:1604-1609, March 17, 1989. 
Manning, Willard G., Emmett B. Keeler, Joseph P. Newhouse, Elizabeth M. Sloss and Jeffrey Wasserman, The Costs of Poor Health Habits; Cambridge: Harvard University Press, 1991.

Miller, Vincent P., Caroline R. James, Carla Ernst, François Collin, "Smoking-Attributable Medical Care Costs: Models and Results," Berkeley, California: Berkeley Economic Research Associates, September 3, 1997 (available on the web at www.bera.com).

Miller, Vincent P., Caroline James, Carla Ernst, Francois Collins, "Measuring the Medical Costs of Smoking in the USA," Social Science and Medicine, 48:375-391, 1999.

Miller Leonard, et. al, "State Estimates of Medicaid Expenditures Attributable to Cigarette Smoking, Fiscal Year, 1998.” Public Health Reports 113 (March-April), 1998.

Napier K., “Cigarettes: What the Warning Label Doesn't Tell You. The First Comprehensive Guide to the Health Consequences of Smoking," New York: American Council on Science and Health, 1996.

Newhouse, Joseph P., "Medical Care Costs: How Much Welfare Loss?" Journal of Economic Perspectives, 6:3, pp. 3-21, Summer 1992.

Newhouse, Joseph P. and the Insurance Experiment Group, Free for All? Lessons from the RAND Health Insurance Experiment; Cambridge: Harvard University Press, 1993.

Rosenthal, Meredith B., David M. Cutler, Richard G. Frank, Raymond S. Hartman, Mary Beth Landrum, and Joseph P. Newhouse, "Estimating the Costs of Public Health Evils Using Observational Data," forthcoming.

Rubin, Donald, State of Minnesota District Court, Second Judicial District, Transcript of Proceedings, pp. 14852-15087, May 1, 1998.

Shoven John.B., J.O. Sundberg, and John P. Bunker, "The Social Security Cost of Smoking." Economics of Aging D. Wide (ed), Chicago, University of Chicago Press, pp. 231-253, 1989.

Stellman, S. D. and L. Garfinkel, "Smoking Habits and Tar Levels in a New American Society: Prospective Study of 1.2 Million Men and Women," Journal of the National Cancer Institute, 76:1057-1063, 1986.

Tobacco Control Resource Center, Northeastern University, "The AG Settlement," http://www.tobacco.neu.edu/Extra/analysis_of_MSA.htm. November 18, 1998.

U.S. Department of Health, Education and Welfare, Smoking and Health: A Report of the Surgeon General. DHEW Publication No. (PHS)79-50066. Washington, DC: Public Health Service, 1979.

U.S. Department of Health and Human Services, 1989 Surgeon General's Report; Washington, DC: Public Health Service, 1989. 
Viscusi, W. Kip., "Cigarette Taxation and the Social Consequences of Smoking", Tax Policy and the Economy, edited by James M. Poterba, 9, 51-101, 1995.

Viscusi, W.Kip, "The Government Composition of the Insurance Cost of Smoking." Journal of Law and Economics XLII (October), 575-609, 1999. 
TABle 1. Medicaid SPEnding by TyPe OF SERVICE, 1992-97

(Millions OF DOLlaRS)

\begin{tabular}{lrrrrrrr}
\hline Category & 1992 & 1993 & 1994 & 1995 & 1996 & 1997 & Total \\
\hline Inpatient & $\$ 1,183$ & $\$ 1,087$ & $\$ 1,113$ & $\$ 1,167$ & $\$ 1,068$ & $\$ 1,073$ & $\$ 6,691$ \\
Outpatient & 724 & 687 & 757 & 817 & 846 & 969 & 4,800 \\
Long-term care & 1,596 & 1,614 & 2,198 & 2,343 & 2,402 & 2,484 & 12,637 \\
Other Acute & 229 & 276 & 375 & 469 & 443 & 940 & 2,732 \\
Non-attributable & 418 & 562 & 572 & 537 & 551 & 461 & 3,101 \\
Total & 4,150 & 4,226 & 5,015 & 5,333 & 5,310 & 5,927 & 29,961 \\
\hline
\end{tabular}

Note: See text for description. 
Table 2. Smoking Prevalence in Massachusetts and the Nation, MEDICAID RECIPIENTS AgED 18+

\begin{tabular}{|c|c|c|c|c|c|c|}
\hline \multirow[b]{3}{*}{ Group } & \multicolumn{6}{|c|}{ Smoking Prevalence } \\
\hline & \multicolumn{3}{|c|}{ Current Smokers } & \multicolumn{3}{|c|}{ Former Smokers } \\
\hline & MA & Nation & $\begin{array}{c}\text { Ratio: } \\
\text { MA/Nation }\end{array}$ & MA & Nation & $\begin{array}{c}\text { Ratio: } \\
\text { MA/Nation }\end{array}$ \\
\hline \multicolumn{7}{|c|}{ Medicaid Population } \\
\hline Men & $42.8 \%$ & $45.5 \%$ & 0.94 & $27.9 \%$ & $24.3 \%$ & 1.15 \\
\hline Women & 39.1 & 35.7 & 1.09 & 25.3 & 12.7 & 1.99 \\
\hline \multicolumn{7}{|c|}{ Population with Income Below \$10,000 } \\
\hline Men & $31.5 \%$ & $38.7 \%$ & 0.81 & $24.9 \%$ & $21.1 \%$ & 1.18 \\
\hline Women & 27.9 & 28.5 & 0.98 & 21.3 & 14.2 & 1.50 \\
\hline \multicolumn{7}{|c|}{ Population with Income Below \$20,000 } \\
\hline Men & $28.9 \%$ & $35.8 \%$ & 0.81 & $26.7 \%$ & $26.5 \%$ & 1.01 \\
\hline Women & 27.3 & 27.6 & 0.99 & 22.1 & 15.8 & 1.40 \\
\hline \multicolumn{7}{|c|}{ Total Population } \\
\hline Men & $24.1 \%$ & $28.3 \%$ & 0.85 & $31.7 \%$ & $29.5 \%$ & 1.07 \\
\hline Women & 21.3 & 23.4 & 0.91 & 29.3 & 19.2 & 1.52 \\
\hline
\end{tabular}


TAble 3: EfFect of SMoking on The USE OF Medical SeRvices NHIS Pooled 1990-1994 Medicaid Sample

\begin{tabular}{|c|c|c|c|c|}
\hline & \multicolumn{2}{|c|}{ Men } & \multicolumn{2}{|c|}{ Women } \\
\hline & $\begin{array}{c}\text { Physician } \\
\text { Visits }\end{array}$ & $\begin{array}{c}\text { Hospital } \\
\text { Days }\end{array}$ & $\begin{array}{l}\text { Physician } \\
\text { Visits }\end{array}$ & $\begin{array}{c}\text { Hospital } \\
\text { Days }\end{array}$ \\
\hline \multicolumn{5}{|c|}{ Probability of Use (relative to never smoker) } \\
\hline Current smokers & $\begin{array}{l}-0.069 \\
(0.015)\end{array}$ & $\begin{array}{c}0.127 \\
(0.023)\end{array}$ & $\begin{array}{l}-0.076 \\
(0.014)\end{array}$ & $\begin{array}{c}0.083 \\
(0.019)\end{array}$ \\
\hline Former smokers & $\begin{array}{c}0.083 \\
(0.016)\end{array}$ & $\begin{array}{c}0.149 \\
(0.022)\end{array}$ & $\begin{array}{c}0.156 \\
(0.016)\end{array}$ & $\begin{array}{c}0.125 \\
(0.019)\end{array}$ \\
\hline $\mathrm{N}$ & 52,126 & 52,344 & 69,643 & 68,926 \\
\hline \multicolumn{5}{|c|}{$\log ($ Use if any use) (relative to never smoker) } \\
\hline Current smokers & $\begin{array}{c}0.056 \\
(0.013)\end{array}$ & $\begin{array}{c}0.092 \\
(0.046)\end{array}$ & $\begin{array}{c}0.050 \\
(0.011)\end{array}$ & $\begin{array}{c}0.085 \\
(0.033)\end{array}$ \\
\hline Former smokers & $\begin{array}{c}0.092 \\
(0.012)\end{array}$ & $\begin{array}{c}0.166 \\
(0.042)\end{array}$ & $\begin{array}{c}0.121 \\
(0.011)\end{array}$ & $\begin{array}{c}0.059 \\
(0.031)\end{array}$ \\
\hline $\mathrm{N}$ & 36,389 & 3,894 & 58,701 & 5,752 \\
\hline \multicolumn{5}{|c|}{ Excess utilization (relative to never smoker) } \\
\hline Current smokers & $3.5 \%$ & $31.0 \%$ & $3.4 \%$ & $23.6 \%$ \\
\hline Former smokers & $11.5 \%$ & $42.4 \%$ & $15.8 \%$ & $25.9 \%$ \\
\hline
\end{tabular}

Note: Standard errors are in parentheses. 
Table 4. EfFect of Smoking on Medical Care Utilization, With AND Without AdDitional ConTrol VARIAbles, 1991 NHIS

\begin{tabular}{|c|c|c|c|c|}
\hline \multirow[b]{2}{*}{$\begin{array}{l}\text { Utilization of smokers relative to their } \\
\text { utilization if they were never smokers }\end{array}$} & \multicolumn{2}{|c|}{ Men } & \multicolumn{2}{|c|}{ Women } \\
\hline & $\begin{array}{l}\text { Physician } \\
\text { Visits } \\
\end{array}$ & $\begin{array}{c}\text { Hospital } \\
\text { Days }\end{array}$ & $\begin{array}{l}\text { Physician } \\
\text { Visits }\end{array}$ & $\begin{array}{c}\text { Hospital } \\
\text { Days }\end{array}$ \\
\hline \multicolumn{5}{|l|}{ Current smokers } \\
\hline With additional variables & $3.1 \%$ & $-5.4 \%$ & $10.4 \%$ & $47.2 \%$ \\
\hline Without additional variables & 5.9 & -5.3 & 7.6 & 48.9 \\
\hline \multicolumn{5}{|l|}{ Former smokers } \\
\hline With additional variables & $10.1 \%$ & $34.7 \%$ & $17.9 \%$ & $46.5 \%$ \\
\hline Without additional variables & 13.4 & 30.7 & 16.0 & 42.6 \\
\hline
\end{tabular}


Table 5. Smoking-Attributable Fractions of Acute Care Service Utilization

\begin{tabular}{lrc} 
& Men & Women \\
\cline { 2 - 3 } $\begin{array}{l}\text { Physician } \\
\text { visits } \\
\text { Hospital days }\end{array}$ & $2.5 \%$ & $6.7 \%$ \\
\hline \hline
\end{tabular}


Table 6. Smoking Attributable Fractions and Spending for Adult Acute Care by Disease

\begin{tabular}{|c|c|c|c|c|c|c|c|}
\hline \multirow[b]{2}{*}{ Condition (ICD-9 code) } & \multicolumn{3}{|c|}{1998 SAFs: Females } & \multicolumn{3}{|c|}{1998 SAFs: Males } & \multirow{2}{*}{$\begin{array}{c}\text { Smoking-Attrib- } \\
\text { table Spending, } \\
1991-98\end{array}$} \\
\hline & $18-44$ & $45-64$ & $65+$ & $18-44$ & $45-64$ & $65+$ & \\
\hline \multicolumn{8}{|l|}{ Neoplasms } \\
\hline Lip, Oral cavity, Pharynx (140-149) & $71 \%$ & $71 \%$ & $58 \%$ & $93 \%$ & $94 \%$ & $91 \%$ & $\$ 12,162,083$ \\
\hline Esophagus (150) & 82 & 71 & 68 & 78 & 83 & 80 & $5,571,508$ \\
\hline Pancreas (157) & 43 & 81 & 33 & 35 & 36 & 25 & $1,914,109$ \\
\hline Larynx (161) & 91 & 44 & 87 & 83 & 85 & 82 & $4,490,503$ \\
\hline Trachea, Lung, Bronchus (162) & 85 & 91 & 75 & 91 & 93 & 90 & $35,038,669$ \\
\hline Cervix uteri (180) & 41 & 85 & 34 & -- & -- & -- & $5,202,063$ \\
\hline Urinary bladder (188) & 46 & 43 & 35 & 48 & 54 & 48 & $4,488,465$ \\
\hline Kidney, Other urinary (189) & 18 & 18 & 11 & 50 & 55 & 49 & $1,526,458$ \\
\hline \multicolumn{8}{|l|}{ Cardiovascular Diseases } \\
\hline Hypertensive heart disease $(402,404)$ & -- & 24 & 14 & 30 & 28 & 45 & $2,708,183$ \\
\hline Ischemic heart disease $(410-414)$ & 50 & 48 & 16 & 47 & 52 & 23 & $86,546,722$ \\
\hline Other heart disease $(415-417,428)$ & 25 & 24 & 14 & 30 & 34 & 27 & $56,738,486$ \\
\hline Cerebrovascular disease (430-438) & 64 & 62 & 7 & 56 & 58 & 27 & $126,236,632$ \\
\hline Atherosclerosis $(440)$ & 49 & 47 & 30 & 61 & 65 & 59 & $19,583,604$ \\
\hline Aortic aneurysm (441) & 49 & 47 & 30 & 61 & 65 & 59 & $4,075,073$ \\
\hline Other arterial disease (442-448) & 49 & 47 & 30 & 61 & 65 & 59 & $41,080,650$ \\
\hline \multicolumn{8}{|l|}{ Respiratory Diseases } \\
\hline Pneumonia, influenza (480-487) & 38 & 37 & 24 & 34 & 40 & 34 & $167,357,828$ \\
\hline Bronchitis, emphysema (490-492) & 84 & 85 & 78 & 83 & 87 & 86 & $161,151,757$ \\
\hline Asthma (493) & 38 & 37 & 24 & 34 & 40 & 34 & $69,822,787$ \\
\hline Chronic airways obstructions (496) & 84 & 85 & 78 & 83 & 87 & 86 & $117,761,939$ \\
\hline Total & & & & & & & $\$ 923,457,516$ \\
\hline
\end{tabular}


TAble 7. SMoking Attributable Fractions and Spending for Long Term Care by Disease

\begin{tabular}{|c|c|c|c|c|c|c|c|c|}
\hline \multirow[b]{2}{*}{ Condition (ICD-9 code) } & \multicolumn{2}{|c|}{$\begin{array}{c}\text { Share of Nursing } \\
\text { Home Stays }\end{array}$} & \multicolumn{2}{|c|}{$\begin{array}{l}\text { Smoking-Attributable } \\
\text { Share of Condition, } 1998\end{array}$} & \multicolumn{2}{|c|}{$\begin{array}{l}\text { Share of Nursing Home } \\
\text { Stays Resulting from } \\
\text { Smoking, } 1998\end{array}$} & \multicolumn{2}{|c|}{$\begin{array}{l}\text { Smoking-Attributable } \\
\text { Spending, 1991-98 } \\
\text { (\$ Millions) }\end{array}$} \\
\hline & Men & Women & Men & Women & Men & Women & Men & Women \\
\hline \multicolumn{9}{|l|}{ Neoplasms } \\
\hline Lip, Oral cavity, Pharynx (140-149) & $0.2 \%$ & $0.0 \%$ & $92.6 \%$ & $65.1 \%$ & $0.1 \%$ & $0.0 \%$ & $\$ 4.9$ & $\$ 0.0$ \\
\hline Esophagus $(150)$ & 0.0 & 0.0 & 81.5 & 76.0 & 0.0 & 0.0 & 0.0 & 0.0 \\
\hline Pancreas (157) & 0.0 & 0.0 & 30.6 & 38.5 & 0.0 & 0.0 & 0.0 & 0.0 \\
\hline Larynx (161) & 0.0 & 0.0 & 83.6 & 89.2 & 0.0 & 0.0 & 0.0 & 0.0 \\
\hline Trachea, Lung, Bronchus (162) & 0.6 & 0.1 & 91.7 & 80.6 & 0.4 & 0.1 & 14.6 & 6.5 \\
\hline Cervix uteri (180) & 0.0 & 0.0 & - & 38.9 & - & 0.0 & 0.0 & 0.0 \\
\hline Urinary bladder $(188)$ & 0.1 & 0.0 & 50.8 & 41.7 & 0.1 & 0.0 & 1.3 & 0.0 \\
\hline Kidney, Other urinary (189) & 0.0 & 0.0 & 52.0 & 14.1 & 0.0 & 0.0 & 0.0 & 0.0 \\
\hline \multicolumn{9}{|l|}{ Cardiovascular Diseases } \\
\hline Hypertensive heart disease $(402,404)$ & 0.1 & 0.1 & 30.1 & 19.1 & 0.0 & 0.0 & 0.8 & 1.5 \\
\hline Ischemic heart disease (410-414) & & & & & & & 0.0 & 0.0 \\
\hline Ages 45-64 & 0.0 & 2.0 & 52.4 & 46.2 & 0.2 & 0.3 & 0.0 & 41.0 \\
\hline Ages $64+$ & 2.4 & 3.9 & 22.9 & 29.8 & 0.1 & 0.2 & 12.6 & 51.5 \\
\hline Other heart disease $(415-417,428)$ & 4.4 & 4.3 & 30.1 & 19.1 & 1.2 & 0.8 & 35.1 & 66.1 \\
\hline \multicolumn{9}{|l|}{ Cerebrovascular disease $(430-438)$} \\
\hline Ages 45-64 & 9.7 & 9.3 & 57.7 & 59.8 & 5.6 & 5.6 & 61.5 & 65.1 \\
\hline Ages $65+$ & 13.1 & 9.4 & 26.5 & 6.7 & 3.5 & 0.6 & 38.1 & 7.4 \\
\hline Atherosclerosis (440) & 0.4 & 0.5 & 62.0 & 39.0 & 0.3 & 0.2 & 6.6 & 15.7 \\
\hline Aortic aneurysm (441) & 0.4 & 0.1 & 62.0 & 39.0 & 0.3 & 0.0 & 6.6 & 3.1 \\
\hline Other arterial disease (442-448) & 1.0 & 0.4 & 62.0 & 39.0 & 0.6 & 0.2 & 16.4 & 12.6 \\
\hline \multicolumn{9}{|l|}{ Respiratory Diseases } \\
\hline Pneumonia, influenza (480-487) & 0.0 & 0.0 & 36.9 & 30.7 & 0.0 & 0.0 & 0.0 & 0.0 \\
\hline Bronchitis, emphysema (490-492) & 0.9 & 0.6 & 86.5 & 82.3 & 0.8 & 0.5 & 20.7 & 39.7 \\
\hline Asthma (493) & 0.3 & 0.3 & 36.9 & 30.7 & 0.1 & 0.1 & 2.9 & 7.4 \\
\hline Chronic airways obstructions (496) & 3.0 & 1.4 & 86.5 & 82.3 & 2.6 & 1.2 & 68.8 & 92.7 \\
\hline Total & & & & & $11.0 \%$ & $5.1 \%$ & $\$ 291.1$ & $\$ 410.4$ \\
\hline
\end{tabular}

